\title{
ICT Professional development for teachers in online forums: analysing the role of discussion
}

\begin{abstract}
This paper explores the role of engaging teachers in constructive dialogue within ICT professional development activity. As part of an ICT professional development program, sixteen teachers across eight geographically removed schools participated in an online threaded discussion forum for a school year. Data reported in this paper are generated from the archived posts to a threaded discussion forum and are analysed qualitatively for evidence of community and quantitatively for different forums of feedback (Mäkitalo, Häkkinen, Leinonen , \& Järvelä, 2002) and levels of discussion (Jarvela \& Hakkinen, 2002). The findings suggest evidence of both collegial and critical forms of discussion. Collegial discussion was found to be important in developing and maintaining community while critical discussion was vital for its role in transforming teachers' beliefs. The data also revealed a number of practical aspects of online environments that inhibit what is termed in this paper as constructive discussion.
\end{abstract}

ICT professional development, ICT pedagogy, Online forums, community of practice

\section{Introduction}

Information and Communication Technologies (ICT) professional development predominantly refers to teacher professional development programs related to computer-based devices. What constitutes effective models of teacher ICT professional development is highly contested (Becher 1999; Knight 2002; Schulman 1987). Long standing perceptions of ICT professional development as skill workshops or training approaches indicate a 're-tooling' of teachers that tends to augment the existing curriculum by developing teachers' competencies focused on specific types of ICT applications. These 're-tooling' models serve to reinforce teachers' approach to integrate ICT without changing their pedagogy. Lankshear and Bigum (1998) have described this as a 'technologised' approach, and later Bigum (2002) refers more poignantly to such practices as 'domesticating' the computer in classrooms. O'Rourke (2001 p.13) redirects ICT professional development towards helping teachers "to focus on pedagogy than on the technology itself" which is affirmed by Loveless (2003 p.324) through her premise to build teachers' "confidence in change...rather than evidence of [ICT] competence". As this movement has progressed, Fisher, Higgins and Loveless (2006) call for a cultural change, a 'renaissance', affirming a redefinition of teacher practice to work in new ways, to collaborate and focus on high task complexity and continuous learning (Loveless 2008; Prestridge 2007). If we have any hope of enabling our teachers to use ICT in ways that will capture new learning styles and pathways of student living in a digital culture, ICT professional development intentions need to move from 're-tooling' with infrequent curriculum integration to a model that will enable teachers to see the 'transforming' possibilities of ICT.

Communication technologies have been promoted as a platform that provides opportunities for learning communities, enabling many-to-many communication that is not place or time dependent (Rovai 2002; King 2002). However, as Zhao and Rop (2001 p.5) illustrate 'the claims and research in this area raises far more questions than it answers'. Literature relating to online learning communities frequently focuses on higher education (Caverly \& MacDonald 2002; Lieblein 2001; Pearson 1999) or distance education (Clark 2001; Rovai 2002) and explores characteristics that help 
maintain and facilitate discussion and learning in these fields of education. However, these characteristics do not necessarily relate to an online learning community of teachers because there is no specific course structure to support and provide a purpose for the community. Literature around online professional development of teachers does not necessarily focus on analysis of the professional development in this mode, that is, quality of teachers' pedagogical discussions that occur. Rather ICT is acknowledged as the tool to facilitate the online context. Starting to emerge from the literature is the role of online learning within ICT professional development as the reformation from a re-tooling orientation to a concern for transformative outcomes of ICT professional development (such as in Henderson 2007). This paper contributes to this emerging understanding of online ICT professional development for transformation of teachers' pedagogy.

\section{Background}

This paper reports on one aspect of a research project that had as its goal the development of a model of teacher ICT professional development that could enable teachers to transform their pedagogical beliefs and practices. The research partners were a coalition of schools called The Suncoast Cyberschools. Their purpose is to establish an education model for communities of the future through the exploration of a curriculum that is embedded in authentic pedagogy and is aligned to a notion of community; the concept of a learning community; and enhancing teacher professionalism. The research project matched will with these aims and commitments. Eight of the ten primary schools (preparatory to grade 7) volunteered teachers for this research.

The research project had two stages. Stage 1 involved the collection of data to inform the design of ICT professional development activity for implementation and analysis in Stage 2. Semi-structured interviews were the main data collection device in Stage 1. Interviews were held with teachers, ICT leaders and principals from the eight schools. Questions were focused on teacher beliefs about ICT and types of ICT professional development that was beneficial. Observations of ICT integration within sixteen classrooms also contributed to this baseline data. Stage 2 utilised action research methodology to support the collaborative design, implementation and evaluation of an ICT professional development activity over a school year.

A key finding of baseline data in Stage 1 suggested that enabling teachers to talk critically to one another is an important professional development process. In Stage 2 teachers' classroom inquiries became the focal professional development activity upon which they engaged in discussion both face to face and in an online mode. Teams of two teachers from the eight primary schools volunteered to be participants in the professional development program. Of the team of two teachers, one offered a supporting role to the other teacher that implemented the classroom inquiry. The teacher implementing a classroom inquiry focused their investigation on analysising their ICT pedagogical beliefs and practices. From baseline data, these teachers were predominantly experienced female practitioners with little to average ICT competency. An asynchronous threaded discussion forum was one opportunity used to engage teachers in group discussion and to enhance the development of community amongst all teachers across the eight schools. This online discussion forum provided a wider audience likely to enable teachers to talk critically about their pedagogy, which 
could lead to change in their teaching practice towards embedding ICT. The threaded discussion forum was implemented via the forum communication tool in a Blackboard $\mathbb{C}$ environment.

All names used in the data reported in this paper have been replaced with pseudonyms and online postings have been copied in full with spelling errors included for authenticity. Corrections are made in brackets to help keep the flow and meaning of the teachers' posts.

\section{Theoretical framework}

This paper is concerned with understanding collegial dialogue as a professional learning activity and its role in enabling teachers to change their ICT beliefs and practices. Collegial dialogue was one of three professional learning activities investigated as a transformative element within a theoretically constructed model for ICT professional development (see Figure 1). The other two professional learning activities were investigation and reflection. This theoretical model was implemented in a practical form through classroom inquiries in the participating schools. Part of the examination of collegial dialogue, through its application within an online forum, is reported here. Collegial discussion was renamed constructive dialogue as a result of data analysis. An amended ICT professional development model evolved and the role of constructive dialogue will be explained in detail towards the end of this paper.

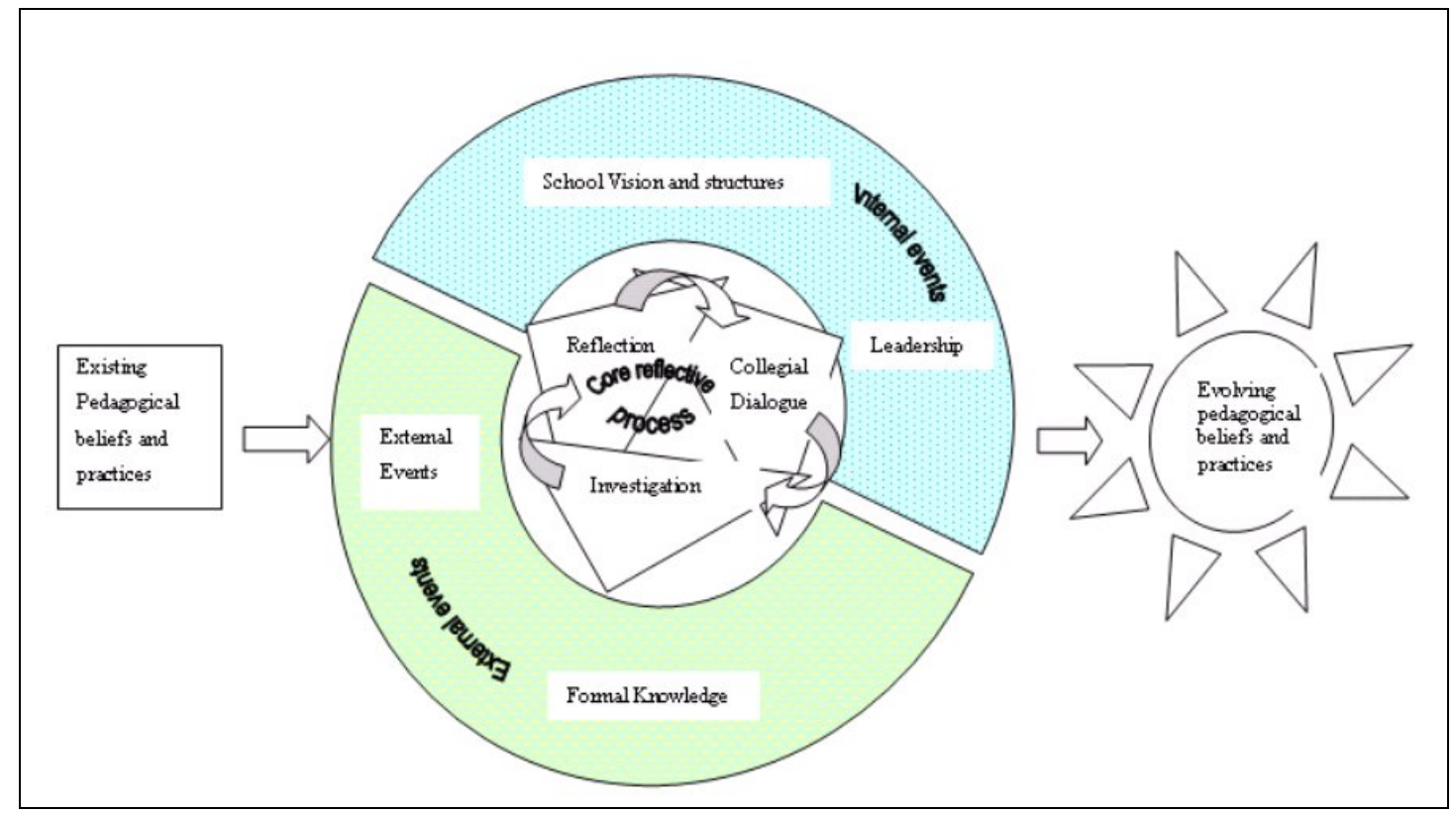

Figure 1 Theoretical ICT professional development model

The professional development activity of collegial dialogue accentuates space for teachers' professional talk about their beliefs and classroom practice. Advocates define collegial dialogue on the basis of sustained interaction by teachers who seek potentially better ideas, indicating critical reflective and inquiring processes (Ball \& Cohen 1999; Fullan 2003; Guskey 2003; Smyth 1987). As the term suggests, collegial dialogue necessitates the formation of a group or 'community' for teacher 
professional development. Learning communities, teacher networks or collaboratives, provide organised social spaces for collegial dialogue. The notion of community is explained by Sagor (1997 p.172) as a "critical unit of change within education". As an ICT professional development activity, the capacity for teachers' engagement in collegial dialogue is relevant to the development of a learning community.

Literature in this area acknowledges that learning communities require group commitment to long-term needs but must also focus on the daily problems and issues to sustain involvement (Lieberman 2000). Learning communities have been found to facilitate teachers' knowledge construction if they are able to evaluate collusions and collisions as part of the learning experiences of a group (Fletcher and Hill 2004). Learning communities have been found to enable teachers to work together to improve practice (McLaughlin and Zarrow 2001). It was with this intention that a learning community was established to sustain a culture of continuous deliberation. In an ICT professional development model, the capacity for teachers' engagement in collegial dialogue is relevant to the development of a learning community.

The rationale for developing a community amongst the school teams was to engender a sense of shared purpose in regard to seeking new knowledge and understanding about the integral use of ICT in learning; to provide opportunity to reflect critically on classroom practices; and to counteract the feeling of isolation that would ensue from independent classroom investigations. These purposes are consistent with the essential characteristics of learning communities (Barab \& Duffy 2000; Lieberman 2000).

In the discussion section that follows, collegial dialogue is explored through an analysis of the development of a learning community. Zhop and Rop (2001 p. 11) problematise notions of community in online environments, which are based loosely around being "connected" rather than determining if community actually exists. Dillenbourg (1999) suggests that looking at the collaborations and the learning taking place provides meaning for a learning community. The threaded postings to an online forum are analysed here for evidence of a learning community through forms of feedback and levels of discussion. It is important to establish if teachers learnt about and/or if discussion impacted their ICT beliefs and practices by participating in collegial dialogue in an online mode of communication. Implications are drawn for collegial dialogue as an essential professional learning activity in ICT professional development.

\section{Discussion}

Collegial dialogue is explored through an analysis of the development of a learning community amongst the teachers for evidence of teacher pedagogical understanding and or change. As part of professional development activities teachers participated in an asynchronous threaded discussion forum. This was implemented via the forum communication tool in a Blackboard environment. A total of sixteen teachers from eight different schools participated.

During the implementation phase, a teacher with the support of their school peer would lead and encourage discussion over a two week period. Participation was both initiated and driven by the teachers. Implementation occurred over a school year with nine different discussion topics posted by school teams. It was decided that I would 
lead the first discussion to demonstrate the process. This is in keeping with Manning and Payne's (1993 p.364) suggestion that "the mechanism for growth in the zone [Vygotsky's concept of zone of proximal development] is the actual verbal interaction with a more experienced member of society". However, to improve the sustainability of the community this initial leadership was to be redirected amongst the teachers through subsequent threads. Generally, the number of postings by a given teacher was found to be more prevalent when it was their turn at leading the threaded discussion.

I opened the online forum with an activity (see Figure 2) connected to specific documentation that each teacher needed to submit, to formalize the beginning of their classroom inquiries:

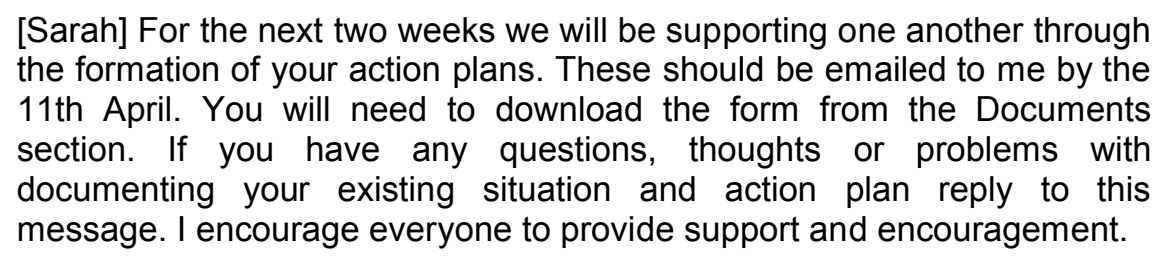
the formation of your action plans. These should be emailed to me by the 11th April. You will need to download the form from the Documents section. If you have any questions, thoughts or problems with documenting your existing situation and action plan reply to this message. I encourage everyone to provide support and encouragement.

Figure 2 Activity posting

Discussion of such documentation was intended to direct initial teacher engagement. For many teachers this was their first experience contributing in an online environment and as such, early responses were of a technical 'trialling nature' to 'test' to see if their postings worked, such as in Figure 3:

[Cherry] Hi all

Just a quick test to make sure I am accessing correctly. David has spent some time preparing and planning our Inquiry Project. Back soon with real discussion.

Figure 3 Trial posting

By its address to "all", this post suggests some acknowledgement of collegiality. It also acknowledges the potential for "real discussion" signifying the purpose for more critical pedagogical postings and having to get the preliminary documentation out the way. The form of address used in the initial postings points to ambiguity with the genre of the forum as a means of communication, between the conversational forms of "hi", the verbal greetings of "g'day" and the written form of "Dear" as would be used in letter format. As the forum progressed the postings tended not to have any form of address, which may have been influenced by familiarity with sequential listings of posts. To keep sense of cross postings, coded names are used in this analysis.

Following this opening for real discussion in Figure 3, I used my 'expert' standing to direct the discussion towards pedagogical issues by replying in Figure 4: 
[Sarah] Thanks Cherry. David has a very hot topic. There has been much discussion about how to use the internet effectively and I think that a Multiliteracy focus is what is required. The internet is a dynamic medium where students use different skills and literacies to make meaning. Looking at it through a multiliterate lens will be really interesting for all of us. Is David planning to use the internet in next terms unit of work. If so what are you planning to do to analyse your pedagogy and learning activities?

Figure 4 My response to trial post

In this posting I was trying to engage Cherry [David's peer] in more constructive discussion by providing background information on effective use of the internet to establish common understanding (Di Mauro \& Jacobs 1995) and directing discussion with a question, signifying a cognitive cue (Mäkitalo et al. 2002). From the use of individual names in these posts and the flow of conversation, it would be expected that the following post would come from Cherry or David. However, evidence of a cross post occurred from Kelly who continued this constructive discourse as in Figure 5:

[Kelly] Questions to clarify and unpack question: What literacies and skills are already being explicitely [explicitly] taught and learnt in present units of work? (Rich Tasks) What literacies and reportoires [repertoires] of practice are needed to use internet effectively? How do you incorporate these needs into your planning and pedagogy?

Figure 5 Kelly's cross post

I responded with more questions in the following post:

[Sarah] Great questions Kelly...would stimulate much thought.

I'll add some:

Why use the Internet?

In what way are you using the Internet? Is this the only way? Is this

appropriate to the learning outcomes you want achieved?

Are there more powerful ways that children can get information than by

surfing the Net? Could discussions with real people in the appropriate

fields be more realistic and educational?

...any experiences others want to share re internet use...

Figure 6 My post of questions

Both Kelly and I instigated further discussion by providing questions that were optional forms of direction for David's inquiry. These questions provided a signal for our willingness to continue the interaction (Mäkitalo et al. 2002) as did my final comment in Figure 6, inviting others to participate. The thread ceased at this point. It could be suggested that at this early stage, within the first week of the online forum, that participants had not established enough common understandings about multiliteracies and ICT to respond to these questions or that confidence or experience in pedagogical application of the internet was lacking. Common understandings of terms such as 'multiliteracies', 'repertoires' or 'pedagogy' seem to be required prior to their application in an online environment to support critical discourse amongst teachers. 
Mäkitalo et al (2002) make a distinction between feedback and questioning in web based discussion. As found here, questions initiate critical discussion whereas feedback is more oriented towards the establishment of a common understanding and the building of relationships in a learning community. These authors propose six different forms of feedback that include agreement/disagreement, personal, notifying, supporting, comparing and paraphrasing. The first two forms of feedback were found to be more common in what Mäkitalo et al (2002) termed progressive level feedback, while the later four forms of feedback were more typical in deeper level discussion. An initial posting to my orientating activity suggests the building of relationships through a personal more jovial tone by Ivy in Figure 7:

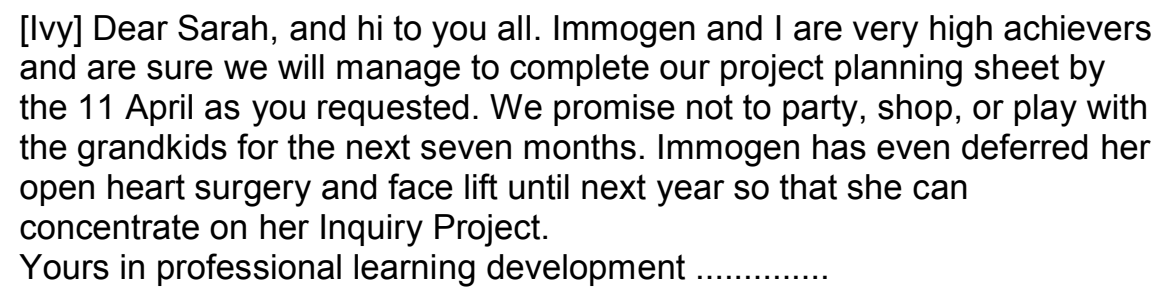

Figure 7 Ivy's jovial posting

Personal feedback by Ivy in her posting conveys positive emotions that set the tone for the development of a learning community. This posting suggests interest and commitment encased in good humour. As an initial posting it supported the development of community.

Di Mauro and Jacobs (1995) suggest that a leader plays a critical role in the building of a cooperative community. In this context I was considered the leader who initially directed the discussion. However, due to the structure of an online forum, where postings and cross postings are unrestricted, this leadership at times devolved into the community. This transfer of responsibility occurred at critical stages where leadership was found to be problematic. An example of this is evident in the following series of postings (Figures 8-14) which I initiated:

[Sarah] Any thoughts or issues associated with monitoring your actions in the first cycle? Has anyone thought about data collection techniques?

Figure 8 My post

The first posting to this question was by Unwin (see Figure 9):

[Unwin] I thought that you might have a checklist of tasks/skills that need to be completed and as this is done you check them off.

Figure 9 Unwin's post

This response is problematic as it is not in keeping with goals of effective integration of ICT for multiliterate outcomes. It places emphasis on teaching about ICT. I am concerned not to alienate Unwin, so I frame my response in the form of questions and seek other comments, removing myself from the expert role (see Figure 10): 
[Sarah] Has anyone any experience with skill checklists? Do they work? It depends on what outcomes you want to achieve and what focus you put on the technology? Comments

Figure 10 My removal from expert role post

Mitchell and Mayer (2002 p.15) suggest caution about comments that can be read as regulatory, serving to "stifle or silence" discussion. Fortunately, the thread was picked up by a teacher, Megan, whose response was more in keeping with the goals of the project (see Figure 11):

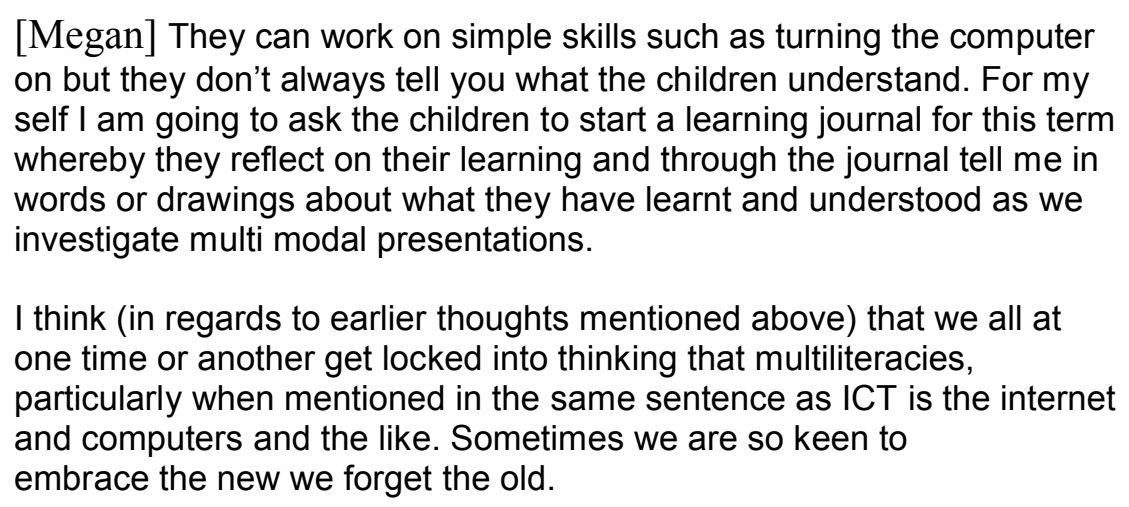

[Megan] They can work on simple skills such as turning the computer on but they don't always tell you what the children understand. For my self I am going to ask the children to start a learning journal for this term whereby they reflect on their learning and through the journal tell me in words or drawings about what they have learnt and understood as we investigate multi modal presentations.

I think (in regards to earlier thoughts mentioned above) that we all at one time or another get locked into thinking that multiliteracies, particularly when mentioned in the same sentence as ICT is the internet and computers and the like. Sometimes we are so keen to embrace the new we forget the old.

Figure 11 Megan's post

Megan used comparing feedback to explain her personal views on the focus of ICT skills. She validates the use of a learning journal as evidence of student understanding. She then enters into a deeper level discussion, drawing on her understanding of multiliteracies and its relationship to ICT. This opens up the opportunity for richer discussion. The following post by Harvey (see Figure 12), two days later, reverted the focus back to an ICT skills checklist:

[Harvey] Checklists can work effectively but we were going to combine ours with an interview and observations, giving the chn. [children] set tasks to perform e.g. make a thank you card for the groundsman then seeing if chn. [children] can perform necessary skills to achieve this. The only problem may be that chn. [children] may learn computer skills sporatically [sporadically] rather than in a sequential manner so the checklist would have to be wide in scope and may not show all the child knows.

Figure 12 Harvey's post

Harvey describes pedagogical practices and beliefs that limit the effective integration of ICT. Learning about ICT through the sequential development of computer skills indicates a technical approach (O'Rourke 2001) or a goal of ICT skills development (Downes et al. 2001). Harvey disregarded Megan's posting, as there was no feedback in Harvey's post. This lack of acknowledgement or loss of thread of discussion is symptomatic of this environment unlike in a face to face environment where a conversation is more easily continued because of notions of time and place. At this 
point, I wanted to encourage discussion and engage Harvey in exploring his beliefs and practices, so I posed a series of questions in Figure 13:

[Sarah] What is the outcome you want to achieve from a thank you card? How does it relate to the concepts under study in the classroom/unit? Is computer skilling at the forefront? Should we be explicitly teaching computer skills? Think this is an important issue to discuss. Comments please

Figure 13 Questions to stimulate Harvey

Once again a response came from another teacher, Kelly (see Figure 14):

[Kelly] Technology skills need to be embedded where possible with some focus teaching for immediate needs as they arise. Peer mentoring is an apt strategy because it allows for most efficient and effective use of time and expertise.

Figure 14 Kelly's post

Harvey did not engage in critical discussion. This thread ended with Kelly's post that reiterated the theme of a focus on learning with ICT, again enabling me to remove myself from the expert role. Suggested reasons for Harvey's disengagement could include a disagreement with or a lack of understanding of the perception being presented in the postings or a lack of confidence or an unwillingness to engage in critical discourse. The online nature of this environment enables participants to engage as 'lurkers' (those that read the posting but do not actively construct a response) or as 'respondents' (both read and respond to a posting).

The transfer of responsibility to lead discussion was also embedded in a design feature for this online forum. As mentioned earlier, each school team was given a two week period to engage and direct discussion on a topic related to the teacher's classroom inquiry. It was found that the quality and level of interaction within topics was dependent upon factors such as interest amongst the community and the generality of the topic. The many to many relationship that exists in this structure enabled an open critical discussion. The following example of a series of postings on the topic 'Is the media the message' started by Unwin enabled critical discussion and a high level of engagement. The number of times that the postings were read also indicates a significant amount of engagement even though it was inactive (lurkers). The postings within this thread are displayed together in Table 1 to mirror the ebb and flow of discussion: 
Table 1 Is the media the message postings

\begin{tabular}{|c|c|c|}
\hline Unwin & $\begin{array}{l}\text { If a teacher is using multi-literacies (apropos [speakers name] excellent presentation at } \\
\text { Nambour RSL) and is a real aficionado of all things techno that whistle, bang and shout } \\
\text { is there a chance that the message will get lost in the media - particularly with young } \\
\text { kids involved? (With acknowledgement to Marshall McLuhan) }\end{array}$ & $\begin{array}{l}\text { Read } 16 \\
\text { times }\end{array}$ \\
\hline Sarah & $\begin{array}{l}\text { You see this a lot when children are searching on the Internet- distracted by the } \\
\text { advertising, or even when they are making a powerpoint presentation- they are } \\
\text { concerned with the animation and sound rather than how powerpoint can enhance the } \\
\text { communication of the concept they are presenting. How are teachers getting past this? }\end{array}$ & $\begin{array}{c}\text { Read } 17 \\
\text { times }\end{array}$ \\
\hline Megan & $\begin{array}{l}\text { This is really difficult. For myself i had two different groups operating in the classroom. } \\
\text { One group on video, the other using powerpoint. The powerpoint group did get } \\
\text { hypnotised by the animation and sound effects and thus some of their message was } \\
\text { lost. The other video group did not - why? Upon reflection I believe that it came down to } \\
\text { the level of input from myself. As the video group was using expensive equipment I } \\
\text { insisted on a huge amount of preplanning, i questioned every thought or idea, asking } \\
\text { them to continually reflect on their plans. Was the idea powerful, would it convince the } \\
\text { audience or would it be lost in the noise or video effect used? Although I monitored the } \\
\text { powerpoint group and made suggestions relating to the use of animation in the } \\
\text { presentation i did not deeply question the children in this group. This, for me, is food for } \\
\text { thought. }\end{array}$ & $\begin{array}{c}\text { Read } 15 \\
\text { times }\end{array}$ \\
\hline Megan & $\begin{array}{l}\text { In our pursuit to be multiliterate classrooms could we be in danger of 'overkill'? Are we } \\
\text { losing the very thing we are trying to achieve due to over saturation? When is enough } \\
\text { enough? }\end{array}$ & $\begin{array}{c}\text { Read } 15 \\
\text { times }\end{array}$ \\
\hline Harry & $\begin{array}{l}\text { New skills, new knowledges and new literacies are features of our New Basics } \\
\text { Curriculum. The excitement and interest that is generated in our students through the } \\
\text { use of multiliteracies is an important enabler for teaching and learning. Many teachers } \\
\text { are learning the skills along with the students, which does consume time, energy and } \\
\text { thought. As teachers and students become more confident and competent with } \\
\text { multiliteracies this will start to balance out. We need to think about how much easier it } \\
\text { will be when we have students with the skills required, teachers with the knowledge and } \\
\text { expertise needed and working reliable technology at our fingertips. We are all on a } \\
\text { journey - I think that multiliteracies integrated into the context of a real student centred } \\
\text { curriculum will always be important and integral to the needs of life long learning. } \\
\text { Overkill won't be the issue. }\end{array}$ & $\begin{array}{c}\text { Read } 8 \\
\text { times }\end{array}$ \\
\hline Unwin & $\begin{array}{l}\text { At a literal level, I think that we can. We must be explicit with what we really want the } \\
\text { students to learn and not get too strung out on the methods of delivery over and above } \\
\text { what is necessary (and here you have to make arbitrary decisions) to get the message } \\
\text { across. I sometimes think we try too hard to do things which in a lot of cases are easy. } \\
\text { I hope that this doesn't sound too flippant in the face of all the stuff at our disposal. } \\
\text { regards }\end{array}$ & $\begin{array}{c}\text { Read } 15 \\
\text { times }\end{array}$ \\
\hline
\end{tabular}

Unwin presents a complex issue in a sociable way. His use of terms such as "all things techno that whistle, bang and shout" provides context for the discussion which helps establish and maintain common ground (Mäkitalo et al. 2002). I respond only once in this thread which indicates the move from a leader to a participatory role. My response uses both supporting and comparing feedback as I provide a pedagogical example to what Unwin is theoretically describing. Megan then moves this discussion into her personal realm where she describes a practical example of how her children are "hypnotised by the animation and sound effects and thus some of their message was lost". Megan then compares two pedagogical approaches and student learning outcomes. She notes that this reflection on her teaching is informative.

Megan continues this discussion in her second posting by putting a negative twist on the use of multiliteracies with the use of terms such as "overkill" and "over saturation". This controversial posting brought both agreement and disagreement feedback. Dillenbourg (1999 p.13) suggests that collaborative learning must provide a space for negotiation and a space for misunderstanding. Mitchell and Mayer (2002 p.17) acknowledge that negotiating meaning enables the possibility of taking conflict and different values into account in our understanding of community. Megan did not reply to either of the posts by Harry or Unwin. The meanings of multiliteracies from each of these postings differed. Harry focused on ICT skills while Unwin was not interested in methods of instruction. This suggests that Megan's intention was 
misunderstood, causing her to disengage from the discussion. Multiliteracies is a complex term that was understood by the teachers in rudimentary form. The thread analysed here indicates some unpacking of multiliteracies through a movement from theory to practice to personal experience. Such unpacking builds common understandings and indicates critical discussion.

This qualitative examination of feedback within postings suggests that an online threaded forum provided an environment where both collegiality and critical discussion existed. Furthermore, in alignment with feedback for lower level and higher level discussion, an examination of the quality of discussion revealed that higher level discussion which involves critique was more prevalent than lower levels of discussion. Using Järvelä's and Häkkinen's (2002) categories of electronic posts, Figure 15 displays the percentage of lower and higher levels of discussions. Järvelä and Häkkinen identify five types of postings that exist on a continuum beginning with comment and suggestion (lower) through to experience, new point/question then theory (higher). It can be seen that 'experience' and 'question' were the most prevalent forms of discussion. This further supports the finding that an online threaded forum provides substantive capacity for critical discussion.

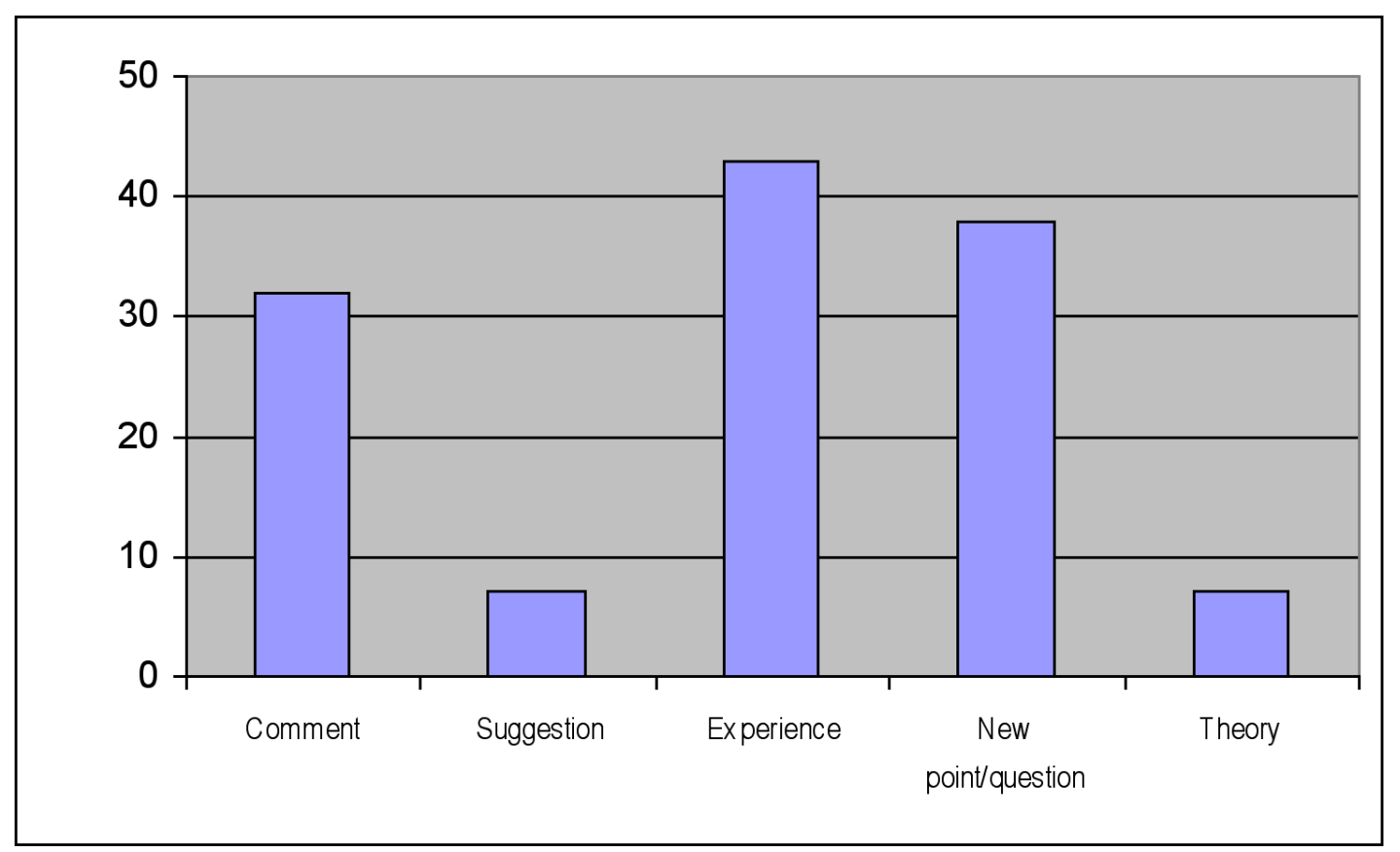

Figure 15 Levels of discussion on threaded forum

\section{Conclusion}

Teachers' postings to an online forum have been analysed in this paper for evidence of a learning community through forms of feedback and levels of discussion. A number of theoretical concepts regarding community and discourse within online environments, as identified by Di Mauro and Jacobs (1995) and Mäkitalo, Häkkinen, Leinonen, and Järvelä (2002) discussed in text, are supported by the data presented here. It would appear that teachers' postings within an online forum facilitated the development of community. Controversy, humour, personal experience and positive feedback all played a valuable role in the development of this online community as they do in other enactments of community. Cross posting, inviting comments and 
sharing the leadership role all served to mirror the dynamics of face to face communication.

Posting were also analysed for evidence of teachers' engagement in the learning process. This was evident in the higher levels of discussion that occurred online. Teachers engaged in discussion where experiences were shared and questions and new points were raised around issues of multiliteracies and ICT. These critical episodes provided a professional learning purpose in the online environment. However, it was found that critical discussion was only sustained for a small number of postings by teachers in a given thread. The data reveal a number of practical aspects of online environments that inhibit critical discussion. These include the opportunities for teachers to 'lurk' or disengage at any given time and the ease with which misunderstandings or comments can silence participation. Alternatively, the role of the leader and the change of leadership are found to have a positive impact on discussion. The development of relationships and common understandings and these symptomatic features of online discussion suggest that the more traditional face to face environment serves specific purposes that can enhance discussion online. As teachers gain more experience in online environments, greater participation and critical discourse could occur without the support of developing prior understandings in face to face settings.

Collegial dialogue as a professional learning activity in ICT professional development has been explored for its role in the development of a learning community where learning implies change to teachers' established understandings about ICT. Underwriting collegial dialogue is the relationship between critical discussion and development of community. Evident in the online environment is the tension that exists between collegial and critical discussion. Tension arises as collegiality is opposed to critique but without critique there is no need for collegiality. In other words, a learning community is built on camaraderie but without the opportunity for learning to occur through critique, there is no point in membership.

In light of the foregrounding analysis, collegial dialogue as a professional learning activity must be renamed to subsume a greater acknowledgement of the transformative capacity of critique. The term 'constructive dialogue' replaces collegial dialogue within ICT professional development to represent this relationship. Teachers' engagement that is collegial establishes a context (community) that enables critical discussion to be formulated and actioned. Consequently, critique becomes a section of collegiality that can be accessed anytime thus impacting on the feeling and purpose of community. The following diagram (Figure 16) depicts the element of constructive dialogue constituting an amended core reflective process in the theoretical model for ICT professional development (Figure 1). 


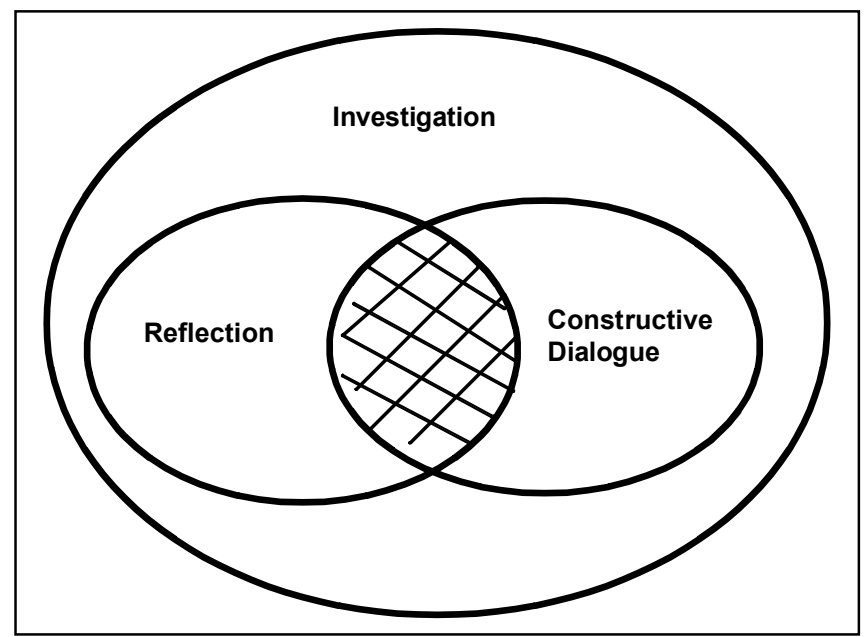

Figure 16 Remodeled Core Reflective Process

In Figure 16 constructive dialogue is represented in two parts. The unshaded section represents collegiality and the shaded section represents critique. Constructive dialogue plays a fundamental role in enabling teachers' to transform their pedagogical beliefs and practices. This paper has reported on one aspect of a research project focused on the development of a model of ICT professional development. It has examined the professional learning activity of teacher dialogue, highlighting both collegial and critical dialogue as necessary elements of discourse to support teachers' to change their beliefs and practices. Constructive dialogue, as termed here, plays an important role in ICT professional development and can be facilitated by online communication tools.

\section{Acknowledgment}

This research is supported by the Australian Research Council, the Suncoast Cyberschools and Griffith University. The contribution of the principals and teachers in the Suncoast Cyberschools is invaluable to this project and is much appreciated by the research team.

\section{References}

Ball, D., \& Cohen, D. 1999. Developing practice, developing practitioners: Towards a practice-based theory of professional education. In L. Darling-Hammond \& G. Skyes (Eds.), Teaching as the learning profession: handbook of policy and practice (pp. 3-32). San Francisco: Jossey-Bass Publishers.

Barab, S., \& Duffy, T. 2000. From practice fields to communities of practice. In D. Jonassen \& S. Land (Eds.), Theoretical foundations of learning environments (pp. 25-55). Mahwah, NJ: Lawrence Erlbaum Associates.

Becher, T. 1999. Professional Practices: Commitment and capability in a changing environment. New Brunswick, NJ: Transaction Publishers.

Bigum, C. 2002. Design sensibilities, schools and the new computing communication technologies. In I. Snyder (Ed.), Silicon Literacies. Communication, 
innovation and education in the electronic age (pp. 130-140). New Fetter Lane, London: Routledge.

Caverly, D. \& MacDonald, L. 2002. Techtalk: Online learning communities. Journal of Developmental Education, 25(3):36- 40.

Clark, J. 2001. Stimulating collaboration and discussion in online learning environments. The Internet and Higher Education, 4(2):119-124. Government, Education Queensland.

Downes, T., A. Fluck, P. Gibbons, R. Leonard, C. Matthews, R. Olivers, M. Vickers and M. Williams. 2001. Making Better Connections: Models of teacher professional development for the integration of information and communication technology into classroom practice. Canberra: Department of Education, Science and Training.

Di Mauro, V., \& Jacobs, G. 1995. Collaborative electronic network building. Journal of Computers in Mathematics and Science, 14, 119-131.

Dillenbourg, P. 1999. Introduction: What do you mean by "collaborative learning"? In P. Dillenbourg (Ed.), Collaborative learning: Cognitive and computational approaches (pp. 1-19). Amsterdam: Pergamon.

Fisher, T., C. Higgins, and A. Loveless. 2006. Teachers learning with digital technologies: A review of research and projects. Bristol: Futurelab

Fletcher, M., and V. Hill. 2004. Partnerships in action: Self-Directed community learning. Paper presented at the 2nd Annual International Conference on Cognition, Language and Special Education, December 3-5, at Gold Coast, Australia.

Fullan, M. 2003. Change Forces with a vengeance. London: Routledge Falmer.

Guskey, T. 2003. Professional Development that works: What makes professional development effective? Phi Delta Kappan, 84(10), 748-751.

Henderson, M. 2007. Shared Repertoire of Communities of Teaching Practice and their role in sustaining online professional development courses. Australian Association for Research in Education Conference 2007. November 2007, Fremantle.

Jarvela, S., \& Hakkinen, P. 2002. Web-based cases in teaching and learning- The quality of discussion and a stage of perspective taking in asynchronous communication. Interactive Learning Environments, 10(1), 1-22.

King, K. 2002. Identifying success in online teacher education and professional development. The Internet and Higher Education, 5(3), 231-246.

Knight, P. 2002. A systematic approach to professional development: leanring as practice. Teaching and Teacher Education, 18(2), 229-241.

Lankshear, C., \& Bigum, C. 1998. Literacies and technologies in school settings: findings from the field. Paper presented at the Australian Association for the Teaching of English and the Australian Literacy Educators' Association, Canberra, Australia, July.

Lieberman, A. 2000. Networks as Learning Communities. Journal of Teacher Education, 51(3), 221-227.

Lieblein, E. 2001. Critical factors for successful delivery of online programs. The Internet and Higher Education, 3(3): Pages 161-174.

Loveless, A. 2003. The interaction between primary teachers' perceptions of ICT and their pedagogy. Education and Information Technologies, 8(4), 313-326.

Loveless, A. 2008. 'Retooling or renaissance?': Teacher education, professional knowledge and a changing landscape. http://www.pef.unilj.si/tepe2008/papers/Loveless.pdf 
Mäkitalo, K., Häkkinen , P., Leinonen , P., \& Järvelä, S. 2002. Mechanisms of common ground in case-based web discussions in teacher education. The Internet and Higher Education, 5(3), 247-265.

Manning, B., \& Payne, B. 1993. A Vygotskian-based theory of teacher cognition: towards the acquisition of mental reflection and self-regulation. Teaching and Teacher Education, 9(4), 361-371.

McLaughlin, M., and J. Zarrow. 2001. Teachers engaged in evidence-based reform: Trajectories of teacher's inquiry, analysis and action. In Teachers caught in the action: Professional development that matters, ed. A. Lieberman and L. Miller, 79-101. New York: Teachers College Press.

Mitchell, J., \& Mayer, D. 2002. Mediating and regulating teacher education discourse: shifting goal posts in an electronic learning community. Paper presented at the Australian Association for Research in Education, Brisbane, December.

O'Rourke, M. 2001. Engaging students through ICT: a multiliteracies approach. Teacher Learning Network Journal: Change, Growth, Innovation, 8(3), 12-13.

Pearson, J. 1999. Electronic networking in initial teacher education: Is a online faculty of education possible? Computers and Education, 32(3):221-38.

Prestridge, S. 2007. Engaging with the transforming possibilities of ICT: A discussion paper. Australian Educational Computing 22, no. 2: 3-9.

Rovai, A. 2002. Sense of community, perceived cognitive learning and persistence in asynchronous learning networks. The Internet and Higher Education, 5(4), 319-332.

Russell, G. 1999. Implications of the 1999 DEST Report for Professional Development in Learning Technology. Paper presented at the ACEC2000, the Australasian Computers in Education Conference, Melbourne, Australia.

Sagor, R. 1997. Collaborative Action Research for Educational Change. In A. Hargreaves (Ed.), Rethinking Educational change with hearts and minds (pp. 169-191). Alexandria: Association for Supervision and Curriculum Development.

Schulman, L. 1987. Knowledge and Teaching: Foundations of the New Reform. Harvard Educational Review, 57(1), 1-22.

Smyth, J. 1987. Transforming teaching through intellectualising the work of teachers. In J. Smyth (Ed.), Educating teachers: Changing the nature of pedagogical knowledge (pp. 155-168). London: The Falmer Press.

Zhao, Y., \& Rop, S. 2001. A critical review of the literature on electronic networks as reflective discourse communities for inservice teachers. Paper presented at the Annual meeting of the American Education Research Association, New Orleans, April. 